\title{
シェル形状モデリングのオイラーモデルに 関する研究*
}

\author{
古川正志** 嘉 数 侑 昇*** 沖 野 教 郎***
}

A Study on Shell Geometric Modelling with the Euler Topology Characteristics

\section{Masashi Furukawa, Yukinori KaKazu and Norio Okino}

The paper represents the shell geometric modelling for sheet metal products and shell structured products. A modelling method for the shell geometry objects adopts the Euler topology based model firstly developed by Baumgart for the solid geometric modelling. The Euler characteristic equation for the shell geometric modelling is derived in the general form as $v-e+f-a=s-h$ and the Euler operations are introduced by the use of the derived equation. The newly developed Euler equation makes it possible to deal with holes and flaps within faces, which are not homeomorphic to the 2-dimensional simplex. Verification to the derived equation is discussed from the view point of the graph theory as well. Some examples show that the new equation is applicable to a variety of shell geometries with the holes and flaps. Furthermore, a surface orientability is discussed and a recognition algorithm is offered to get rid of unoriented surface geometries. This algorithm also makes a difference between inner edges and boundary edges in the shell.

Key words ; geometric modelling, CAD, shell model, Euler operation, boundary representation

\section{1. 緒言}

三次元形状の数学モデルを計算機内部に構築し，工 学的に必要な種々の形状処理問題に対して, この内部 モデルを適用可能とする情報処理を形状モデリングと 呼べば, 形状モデリングは, CAD/CAM，コンピュー タグラフィックスの発展の中で重要な位置を現在占め ている。これは，物を作り出すといら行為が，そのた めに必要な形状情報を作成することを本質的に含み， 形状モデリングを要求していると考兄られるからであ る.

こうして, 形状モデリングに関する多くの研究2) 4) が発表されて来ている。しかし，これらを検討すると その多くの研究は, 立体 (solid) 形状に対するもので ある。一方，現実的な問題として広く多くの分野を眺 望すれば，必ずしも立体による三次元形状表現を取り 报わなくてもよい形状対象が存在する。 それらの例と しては，殼（shell）で構成されるような形状，板金製

* 原稿受付 昭和 59 年 11 月 30 日. 昭和 59 年度精機学会春 季大会学術講演会（昭和 59 年 3 月 25 日）にて発表

** 正会員 旭川工業高等専門学校(旭川市春光台 2 条 2 丁 目)

*** 正 会 員 北海道大学工学部（札幌市北区北 13 条西 8 丁 目)
品, 地図モデル等である。前二者は，厳密にみれば立 体といえるが，その厚みを無視すると，立体によらな い三次元形状表現である。本研究では，こうした厚み のない殼のみで構成される三次元形状（これを単に シェルと呼ぶ) に対して,オイラートポロジーを利用 した形状モデリングの方法論を開発する。すなわち， シェルに対して，そのモデリングを保証する数学モデ ルとなるオイラー方程式を導き，それが種々のシェル 形状に適用可能であることを示す（その中でも特に穴 (hole) やフラップ（flap）の取扱いが可能であること を示す). 次いで, シェル形状の向き付け可能及び不可 能面に関する取扱いと, これによって立体モデルでは 生じない境界辺と内部辺の認識を論じる（図 1).

導入されたオイラー方程式については, シェル形状 モデリングを実施するオイラーオペレータの導出を行 5 .

\section{2. シェル形状モデリングのための オイラー方程式}

シェルは, 三次元ュークリッド空間 $\left(\mathrm{E}^{3}\right)$ の部分集 合としてモデル化される，モデルは，実在する物体を 反映するので, コンパクトでレギュラーな点集合と仮 定する。シェルモデルを表す点集合を $\boldsymbol{X}$ とすれば, 


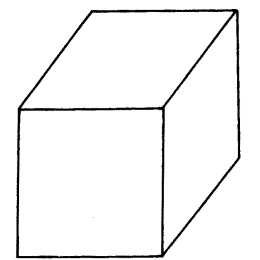

(a) Solid geometric modelling

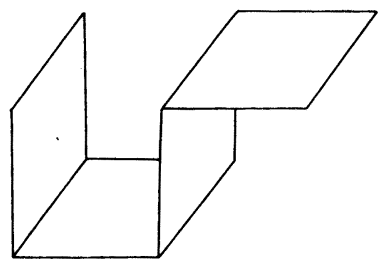

(b) Shell geometric modelling
Fig. 1 Solid and shell geometric modelling

$$
\boldsymbol{X}=\left\{\boldsymbol{P}: \operatorname{Surf}(\boldsymbol{P})=0, \quad \boldsymbol{P} \in \mathrm{E}^{3}\right\}
$$

と表現できる，すなわち，点集合 $\boldsymbol{X}$ は，ある曲面上の 点集合に属する。ここで, Surf は曲面を表す関数であ る. 点集合 $\boldsymbol{X}$ は, トポロジカルな意味で, $\mathrm{E}^{2}$ のコンパ クトでレギュラーな部分集合と等価である.こうして, シェルモデルは, 向きづけられた 0-単体, 1-単体, 2-単 体からなる 2 次元ホモロジー群によって表現される。

シェルモデルのためのオイラー方程式を導くため, 多面体の形状モデリングに採用された Baumgart に より導入されたオイラー方程式)をまず検討する。

Baumgart のオイラー方程式は,

$$
V-E+F=2 B-2 H
$$

である.ここで， $V, E, F, B, H$ は，それぞれ多面体 モデルの頂点数, 辺数, 面数, 立体 (多面体) 数及び穴 （種）数である.シェル形状は, 薄い厚みを持つ立体形 状の厚みを無限小としたものと考えられる。このとき, 厚みを構成する面と辺は消失し, 相対する 2 面は一致 する.この操作を式 (2) に対して行らと,

$$
v=V / 2, e=E / 3, f=F-e, s=B, h=H
$$

の関係が得られる。ここで, $v, e, f, s$ 及び $h$ は, この 結果得られるシェルモデルの頂点数, 辺数, 面数, シェ ル数と穴数とする.式 (3) を式 (2) に代入すると,シェ ルモデルのためのオイラー方程式

$$
2 v-2 e+f-2 s+2 h=0
$$

を得る. 式 (4)で, シェルの面は表裏 2 面を別々に数 えている. 表裏 2 面を 1 面とし，このときの面数を $f^{\prime}$ と置けば, $f=2 f^{\prime}$ だから，これを式 (4) に代入して,

$$
v-e+f^{\prime}-s+h=0
$$

を得る. 以後 $f^{\prime}$ を $f$ と記述し, 式 (5)を

$$
v-e+f-s+h=0
$$

と表す。

シェルモデルのためのオイラー方程式は, 式 (6)に より表現される。しかし，このオイラー方程式は， Baumgart のオイラー方程式が，三次元単体に位相同 形な多面体のみに適用可能であるのと同様, 二次元単 体に位相同形なシェル形状のみに適用可能である. 式 （6）が, 適用可能な場合と不可能な場合を図 2 に示す.
図 2 (g) は面内に穴がある場合であり，図 $2(\mathrm{~h})$ は面 内にフラップがある場合, 図 2 (i) はフラップが一点 で接する場合である。式（6）をこれらの場合に適用す るには，図 3 に示される破線のダミ一辺を作成する必 要がある.このことは, シェルモデルの統一的処理に 不便であるのみならず，面内の穴と面に囲まれた穴を 認識し区別する上でも不都合である。これは，式 (6) が，二次元単体に位相同形であるという制約から生じ ている. 以下に，面内の穴及びフラップを取り扱觉る より一般的なシェルモデルのオイラー方程式を導入す る.

\section{3. シェルモデルの拡張オイラー方程式}

面内の穴及びフラップを面付属単体 (Associate face simplex）と名づける。これらを取り扱らため, 式 (6) を

$$
v_{0}-e_{0}+f_{0}-s_{0}+h_{0}=0
$$

と書き改める。まず，面内に穴がある場合を考学る。 このような穴の数が, シェル全体について $n$ 個あると する. 各穴は, 二次元単体に位相同形であると考学ら れるから, $i$ 番目の穴に関しては,

$$
v_{i}-e_{i}+h_{i}-a_{i}=0
$$

が成立する. 式 (8) は, 式 (6) に関して, 面数の代わ りに穴数を置き，穴数を 0 とし、シェル数の代わりに 面付属単体数 $a_{i}$ を置いたものである. $n$ 個の穴がある 場合, 式 (8)は,

$$
\sum_{i=1}^{n} v_{i}-\sum_{i=1}^{n} e_{i}+\sum_{i=1}^{n} h_{i}-\sum_{i=1}^{n} a_{i}=0
$$

と書ける。式 (7) に式 (9)を加えると

$$
\sum_{i=0}^{n} v_{i}-\sum_{i=0}^{n} e_{i}+f_{0}-s_{0}+\sum_{i=0}^{n} h_{i}-\sum_{i=1}^{n} a_{i}=0
$$

を得る。各項を

$$
\left.\begin{array}{l}
v=\sum_{i=0}^{n} v_{i}, \quad e=\sum_{i=0}^{n} e_{i}, \quad f=f_{0} \\
s=s_{0}, \quad h=\sum_{i=0}^{n} h_{i}, \quad a=\sum_{i=1}^{n} a_{i}
\end{array}\right\}
$$

と置けば, 式 $(10)$ は,

$$
v-e+f-a+h-s=0
$$

となる.式 (12)を適用することで, 面内の穴を処理可 能とできる.

次にフラップについても，穴の取扱いと同じに考兄 よう.フラップの場合は, 式 (8) において, 穴数を面 数と考学ればよい.今， $m$ 個のフラップがあるとすれ ば, $i$ 番目のフラップに関して,

$$
v_{i}-e_{i}+f_{i}-a_{i}=0
$$

が, 式 (8) と同様に成立する. $m$ 個のフラップがある 


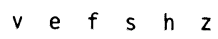

$\begin{array}{llllll}4 & 4 & 1 & 1 & 0 & 0\end{array}$

(a) A sheet (A face)

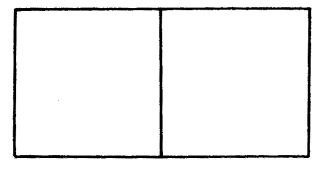

(b) Two faces

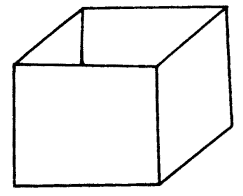

$v$ e f $s$ h $z$

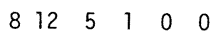

(c) A bin with five faces

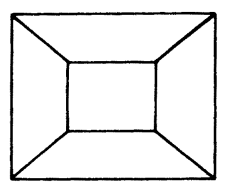

$v e f s h z$

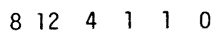

(d) Faces with a hole

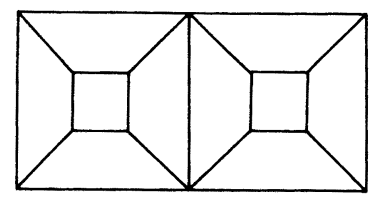

(e) Faces with two holes $v$ e $f$ s $h \quad$ z $\begin{array}{llllll}14 & 23 & 8 & 1 & 2 & 0\end{array}$

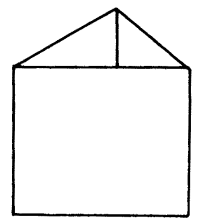

$v$ e f s h z

$\begin{array}{llllll}6 & 9 & 3 & 1 & 1 & 0\end{array}$

(f) A hole surrounded by three faces

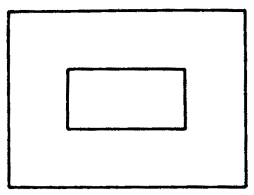

$v$ e f s h z

$\begin{array}{llllll}8 & 8 & 1 & 1 & 1 & 1\end{array}$

(g) A face with a hole

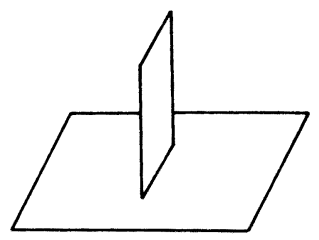

$v$ e f s h $z$

$\begin{array}{llllll}8 & 8 & 2 & 1 & 0 & 1\end{array}$

Fig. 2 Examples applied by the Eq. (6), where $z=v-e+f-s+h$. If $z$ is not equal to zero, the Eq. (6) is not applicable

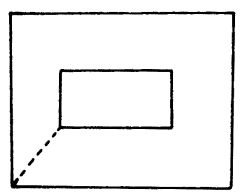

(a) A hole with a dummy edge

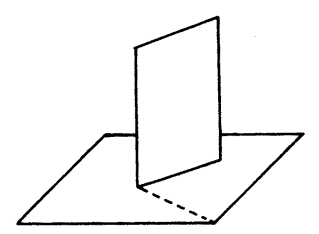

(b) A flap with a dummy edge

Fig. 3 Two cases applicable by the Eq. (6) by adding dummy edges

とすれば, 式 (13) は,

$$
\sum_{i=1}^{m} v_{i}-\sum_{i=1}^{m} e_{i}+\sum_{i=1}^{m} f_{i}-\sum_{i=1}^{m} a_{i}=0
$$

となる. 式 (7) と式 (14) を加えて,

$$
\sum_{i=0}^{m} v_{i}-\sum_{i=0}^{m} e_{i}+\sum_{i=0}^{m} f_{i}-s_{0}+h_{0}-\sum_{i=1}^{m} a_{i}=0
$$

を得る。各項を

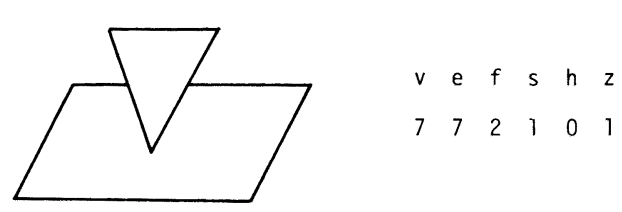

(i) A flap touching a face with a point

\section{(h) A flap}

\section{(6)}




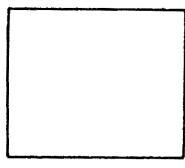

$v$ e $f$ a $h$ z

$\begin{array}{lllllll}4 & 4 & 1 & 0 & 1 & 0 & 0\end{array}$

(a) A sheet

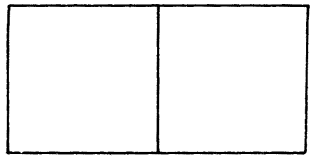

$v$ e $f$ a $s$ h $z$

$\begin{array}{lllllll}6 & 7 & 2 & 0 & 1 & 0 & 0\end{array}$

(b) Two faces

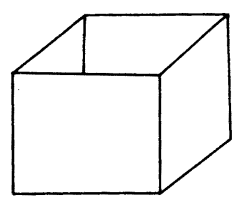

(c) A bin with five faces

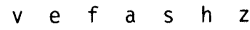

$\begin{array}{lllllll}8 & 12 & 5 & 0 & 1 & 0 & 0\end{array}$

e f a s h $z$

8811110

(d) A face with a hole

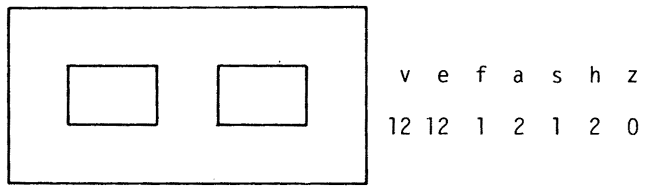

(e) A face with two holes

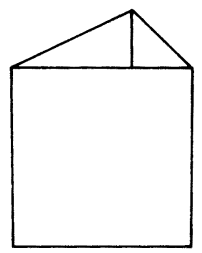

$v$ e $f$ a $h$ z

$\begin{array}{lllllll}6 & 9 & 3 & 0 & 1 & 1 & 0\end{array}$

(f) A hole surrounded by three faces

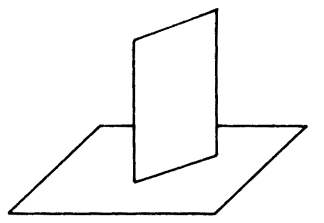

$v$ e $f$ a $s \quad h \quad z$ $\begin{array}{lllllll}8 & 8 & 2 & 1 & 1 & 0 & 0\end{array}$

(g) A flap

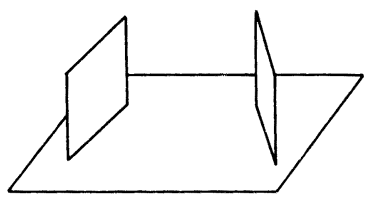

$v$ e $f$ a $s$ h $z$ $\begin{array}{lllllll}12 & 12 & 3 & 2 & 1 & 0 & 0\end{array}$

(h) Two flaps

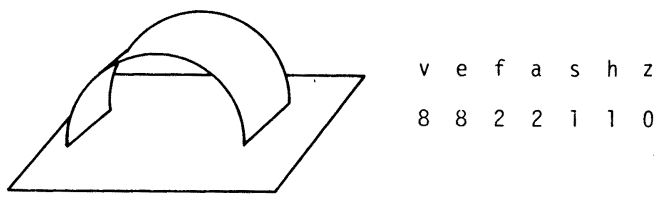

(i) A handle attached on a face

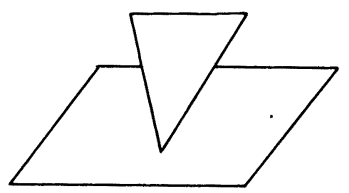

$v$ e f a s $h$ z

$\begin{array}{lllllll}7 & 7 & 2 & 1 & 1 & 0 & 0\end{array}$

(j) A flap touching a face with a point

Fig. 4 Examples applied by the Eq. (17), where $z=v-e+f-a+h-s$

$$
\sum_{i=0}^{2}(-1)^{i} \alpha_{i}=\sum_{i=0}^{2}(-1)^{i} \beta_{i}
$$

として知られる.ここで, $\alpha_{i}$ は $i$ 次元単体の数, $\beta_{i}$ は ベッチ数である.シェル形状が穴を持たず，またフラッ プも持たないとき, 式（18）はシェル形状が円板と位相 同形であることを考えて，

$$
v-e+f=1
$$

が知られている.ここに， $\beta_{0}=1, \beta_{1}=\beta_{2}=0$ である. もし $s$ 個のシェル形状があれば，これらを連結して位 相同形とすればよい.このとき, 図 5 に示すように連 結すると, 頂点, 辺, 面数の関係は,

$$
v-(e+2(s-1))+(f+(s-1))=1
$$

となる。式 (20) を整理すると,

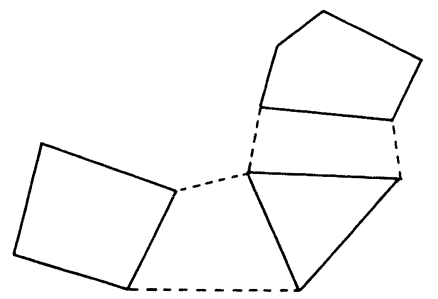

Fig. 5 Joining shells

$$
v-e+f=s
$$

を得る.グラフ理論では $\beta_{0}=s$ (成分数)， $\beta_{1}=\beta_{2}=0$ と して知られている. 次に, 各面がすべて二次元単体に 位相同形で，穴が $h_{0}$ 個ある場合を考えよう。このと 


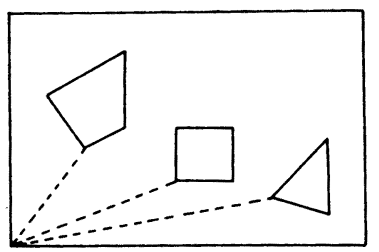

Fig. 6 Imaginary edges joining holes

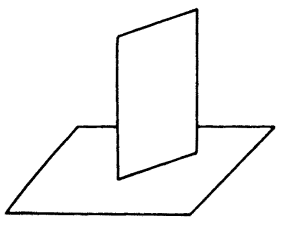

(a) A flap

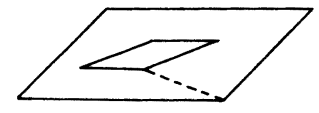

(b) A flap embedded in
a face
Fig. 7 Joining an embedded flap in a face with an imaginary edge

き， $h_{0}$ 個の面で穴をふさげば，シェル形状は，円板と 位相同形となる，このとき，面数は，(f+ho 個とな る。これを式 (21) に適用すると，

$$
v-e+\left(f+h_{0}\right)=s
$$

となり, 整理して

$$
v-e+f=s-h_{0}
$$

を得る。

面内に, $h$ 個の穴のある場合を考学る。このとき， べての面が二次元単体に位相同形であるように，穴を ふさぎ，図6のように仮想の辺を作成する，仮想の辺 数を $a_{h}$ と置き, 式 (23) に適用すると, 辺数は $\left(e+a_{h}\right)$ 個, 面数は $\left(f+h_{1}\right)$ 個 (但し, $\left.a_{h}=h_{1}\right)$ から

$$
v-\left(e+a_{h}\right)+\left(f+h_{1}\right)=s-h_{0}
$$

となり,これを整理して

$$
v-e+f-a_{h}=s-h_{0}-h_{1}
$$

を得る。

フラップがある場合を最後に考える、フラップ数が $f_{f}$ 個あるとしょう. 円板と位相同形とするため, フ ラップを,そのフラップを含む面より小さくし，フラッ プを面内に倒して埋め込むと，面内に一つの面ができ る.これを一つの面と数え,すべての面を二次元単体 と位相同形とするため, 穴の場合と同じょうに $a_{f}$ 個 の仮想辺を，図 7 に示されるように作成する。こうす ると, 辺数は $\left(e+a_{f}\right)$ 個, 面数は $\left(f+f_{f}\right)$ 個 (但し, $\left.a_{f}=f_{f}\right)$ となる. 式 (25) にこれを適用すると,

$v-\left(e+a_{f}\right)+\left(f+f_{f}\right)-a_{h}=s-h_{0}-h_{1}$

となる。これを整理すると，

$$
v-e+\left(f+f_{f}\right)=s-\left(h_{0}+h_{1}\right)+\left(a_{h}+a_{f}\right)
$$

を得る. $f+f_{f}$ を $f, h=h_{0}+h_{1}, a=a_{f}+a_{h}$ とすれば, 式 (27) は,

$$
v-e+f=s-h+a
$$

となり, 式 (17) を得る.

\section{5. シェルオイラーオペレータの導出}

式（17）を

$$
z(\boldsymbol{X})=v-e+f-a+h-s=0
$$

と置さな拉す.オイラーオペレータは, 式 (29) 上の格 子点間の遷移べクトルに相当する. この遷移ベクトル をdとすると, 式 (29) から

$$
\nabla z \cdot d=0
$$

$\nabla z=(v, e, f, a, h, s)$ を得る. 超平面式 (29) は, 六次 元超平面だから，5つの独立なべクトルで張ることが でさる. 今, $\boldsymbol{d}=\sum_{i=1}^{5} t_{i} \cdot \boldsymbol{d}_{i}$ とし, 式 (30)に代入すると,

$$
\nabla z \cdot\left(\sum_{i=1}^{5} t_{i} \cdot \boldsymbol{d}_{i}\right)=0
$$

から,

$$
\nabla z \cdot \boldsymbol{d}_{i}=0, \quad i=1,2, \cdots, 5
$$

を得る. $\boldsymbol{d}_{i}$ の成分を $d_{i j},(j=1,2, \cdots, 6), d_{i j}=0$ 又は 1 とし, これを基本オイラーベクトルと名づければ,す ベてのオイラーオペレータは, 基本オイラーベクトル の組合せに相当する，基本オイラーベクトルに相当す る操作を基本オイラーオペレータと名づけ. 頂点, 辺等の作成に $\mathrm{m}$, 消去に $\mathrm{k}$ を冠し, 基本オイラーベク トルとオペレータを作成すると, 例えば表 1 のように 選ぶことができる。

\section{6. 向き付け不可能面}

立体のモデリングでは, ベッチ数 $\beta_{1}$ を計算し，それ が奇数か偶数かで向き付け不可能な面を含むかどらか を知ることができる。ここで, 向き付け不可能面とは, メービウス帯あるいはクラインの㯺のような表裏の区 別のない面を指す。一方, シェル形状モデリングでは, メービウス帯は, 頂点, 辺等が 2 倍の数を持つ円筒と 位相同形となるため, ベッチ数の計算による識別はで きない。機械設計では，こうした形状は，ほとんど生 じないが計算機内にモデルを作成しようとすれば，そ の可能性が生じる. 従って, これを排除する必要があ る.この識別アルゴリズムは, 以下のように実行でき る.

今, 与えられた曲面のモデルを $A$ と置く，これを三 角形に位相同形な多角形 (面) $A_{i}(i=1,2, \cdots, k)$ に分 割し,

$$
A=\bigcup_{i=1}^{k} A_{i}
$$

とする. $A_{i}$ と $A_{j}$ が隣接しているとすれば, $A_{i}$ と $A_{j}$ は共通辺を持つ. 共通辺を $e_{i j w}(w=1,2, \cdots, l)$ とし, 
Table 1 Basic Euler operators for shell geometric modelling. An afs means Associate Face Simplex in the tabel.

\begin{tabular}{|c|c|c|c|c|c|c|c|}
\hline \multirow{2}{*}{$\begin{array}{l}\begin{array}{l}\text { Euler } \\
\text { operator }\end{array} \\
\end{array}$} & \multicolumn{6}{|c|}{ Transition vector } & \multirow{2}{*}{ Comments } \\
\hline & $v$ & $e$ & & $a$ & $h$ & $s$ & \\
\hline mvs & 1 & 0 & 0 & 0 & 0 & 1 & make vertex, shell \\
\hline mve & 1 & 1 & 0 & 0 & 0 & 0 & make vertex, edge \\
\hline $\mathrm{mvf}$ & 1 & 0 & 1 & 0 & 0 & 1 & make vertex, face \\
\hline meh & 0 & 1 & 0 & 0 & 1 & 0 & make edge, hole \\
\hline meahks & 0 & 1 & 0 & 1 & 1 & -1 & $\begin{array}{l}\text { make edge, afs, hole } \\
\text { kill shell }\end{array}$ \\
\hline meafks & 0 & 1 & 1 & 1 & 0 & -1 & $\begin{array}{l}\text { make edge, afs, face } \\
\text { kill shell }\end{array}$ \\
\hline kvs & -1 & 0 & 0 & 0 & 0 & -1 & kill vertex, shell \\
\hline kve & -1 & -1 & 0 & 0 & 0 & 0 & kill vertex, edge \\
\hline $\mathrm{kvf}$ & -1 & 0 & -1 & 0 & 0 & 0 & kill vertex, face \\
\hline keh & 0 & -1 & 0 & 0 & -1 & 0 & kill edge, hole \\
\hline keahms & 0 & -1 & 0 & -1 & -1 & 1 & $\begin{array}{l}\text { kill edge, asf, hole } \\
\text { make shell }\end{array}$ \\
\hline keafms & 0 & -1 & 1 & -1 & 0 & 1 & $\begin{array}{l}\text { kill edge, asf, face } \\
\text { make shell }\end{array}$ \\
\hline
\end{tabular}

$A_{i}$ に反時計回りに向き付けを行ったとき, $e_{i j w}=1$ と する，次いで， $A_{j}$ に向き付けを行ったとき，

$$
e_{i j w}:=e_{i j w}+d
$$

$d=\left\{\begin{array}{r}-1: A_{i} \text { と } A_{j} \text { における } e_{i j w} \text { の向きが逆方向 } \\ 1: A_{i} \text { と } A_{j} \text { における } e_{i j w} \text { の向きが同方向 }\end{array}\right.$ とする.すべての多角形 $A_{i}$ に対してこの操作を実行 し，もしすべての共通辺の值が 0 となれば，向き付け は可能と識別できる。，一方，一つでも共通辺の值が 2 となるとき，向き付け不可能である。

すべての辺に対してこの処理を実施すると, 向き付 け可能かどらかは,

（1）辺の值がすべて 1 か 0 のとき向き付け可能

（2）辺の值が一つでも 2 となるとき向き付け不可 能

と識別できる。更に，値が 1 の辺は，境界辺としての 認識が可能となる。境界辺とは, 共通辺とならない辺 であり，立体モデリングには生じない辺である。

\section{7. 結}

立体とは異なるシェル形状モデリングのオイラート ポロジーモデルの導入を図り，これから以下のことが 結言される。

（1）シェル形状モデリングを行うのに必要なオイ ラートポロジーモデルのためのオイラー方程式を 導いた。

（2）上で導いたオイラー方程式の拡張を行い, 面内 の穴及びフラップをオイラー方程式で取り扱える ようにした。

（3）オイラー・ポアンカレの式から, 上に導いたオ イラー方程式を検証した。
（4）向き付け不可能面に関する識別アルゴリズム を作成した。

（5）シェル形状モデリングのための基本オイラー オペレータの例を示した。

オイラートポロジーモデルの必要条件は, 頂点一辺, 辺一面, 面一シェルへの連結が正確に記述されているこ とであり,これは, データベースにおいて,グラフベー スドな構造で記述される。（2）に拉いて導入した面付 属単体は, 立体のモデリングでは, リング数に相当す るとも考えられる。

\section{[付 録]}

本文中の以下の用語を簡単に述べる.

単体: $a_{0}, a_{1}, \cdots, a_{r}$ を $n$ 次元ュークリッド空間 $\mathrm{R}^{n}$ $(r \leqq n)$ の独立な点集合とする. 空間 $\mathrm{R}^{n}$ のなかで $x=\lambda_{0} a_{0}+\lambda_{1} a_{1}+\cdots+\lambda_{r} a_{r}$

なる形をした点 $x$ の集合 $A^{r}$ を $r$ 次元単体，あるいは 簡単に $r$ 単体という。ここで $\lambda_{i}(i=0,1, \cdots, r)$ は実数 で, $\lambda_{i} \geqq 0, \sum_{i=0}^{r} \lambda_{i}=1$ である. 0 次元単体は一点, 1 次元 単体は線分, 2 次元単体は三角形, 3 次元単体は四面体 となる。

単体複体：ニークリッド空間 $\mathrm{R}^{n}$ の有限個の単体の集 合 $K$ は，次の条件を満たすとき，単体複体という。

1. $A$ が $K$ の単体ならば， $A$ のすべての辺単体は また $K$ に入っている.

2. $K$ のどの $2 つ の$ 単体も，それらが交わらない か，それらの交わりは 2 つの単体の共通の辺単体 である。

ここで $s$ 辺単体とは, $A^{r}=\left(a_{0}, a_{1}, \cdots, a_{r}\right)$ を $\mathrm{R}^{n}$ の $r$ 単体とし， $\alpha_{k}=a_{i k}(k=0,1, \cdots, s ; 0 \leqq s \leqq r)$ としたと き，頂点 $\alpha_{0}, \alpha_{1}, \cdots, \alpha_{s}$ からなる単体である.

多面体：Kをユークリッド空間 $\mathrm{R}^{n}$ のなかの単体複体 とする.この $K$ の単体に属するすべての点の集合は, 多面体といわれる。

位相同形： $A, B$ をユークリッド空間 $\mathrm{R}^{n}$ の部分集合 とする.写像 $\mathrm{f}: A \rightarrow B$ が全単射であって,かつ $\mathrm{f}$ 扰よ び $\mathrm{f}$ の逆写像 $\mathrm{g}: B \rightarrow A$ がともに連続であるとき， $\mathrm{f}$ を位相同形写像といい, $\mathrm{f}$ が存在するとき， $A$ と $B$ は 位相同形とい5. 本文では, 2 次元単体と多角形, 円を 位相同形といっている。

\section{参考 文 献}

1） I. M. シンガーほか：トポロジーと幾何学入門, 培風館 (1976) 157.

2) B. G. Baumgart: Geometric Modelling for Computer Vision, Rep. STA-CS-74-463, Stanford Univ., Stanford, Calf., (1974).

3) I. C. Braid: Note on Geometric Modeller, Univ. of Cambridge, CAD Group Document, No. 101, (1979).

4) H. B. Voelcker et al. : An Introduction to PADL; Characteristics, Status and Rational, Tech. Memo. 22, Production Automation Project, Univ. of Rochester, N. Y., Dec. (1974). 